\title{
Novel Missense Mutation (G314R) in a Cystic Fibrosis Patient With Hepatic Failure
}

\author{
Samya Z. Nasr*, Theresa V. Strong, Monique K. Mansoura, David C. Dawson, \\ and Francis S. Collins \\ Departments of Pediatrics (S.Z.N.), Human Genetics (T.V.S., F.S.C.), Bioengineering (M.K.M.), Physiology (D.C.D.), and \\ Internal Medicine (F.S.C., T.V.S.), University of Michigan, Ann Arbor, Michigan 48109, and National Center for Human \\ Genome Research, Bethesda, Maryland 20892 (F.S.C.); Fax: 313-763-4208 \\ Communicated by Lap-Chee Tsui
}

\section{INTRODUCTION}

Cystic fibrosis is caused by mutations in the gene encoding the cystic fibrosis transmembrane conductance regulator (CFTR) (Kerem et al., 1989; Riordan et al., 1989; Rommens et al., 1989). The clinical manifestations of cystic fibrosis are thought to be related to abnormal chloride conductance due to defective synthesis, processing, or function of CFTR chloride channels (Welsh, 1990; Drumm et al., 1991; Collins , 1992; Welsh et al., 1992; Riordan, 1993). We have identified a novel missense mutation in a native-American/Caucasian patient in exon 7 of the CFTR, by chemical mismatch cleavage of cDNA obtained through reverse transcription of mRNA from nasal scraping.

\section{MATERIALS AND METHODS}

The subject is a 13 -year-old female. Her ethnic background includes Dutch/French from the paternal side and native-American (Cherokee)/Caucasian from the maternal side. She was diagnosed with $\mathrm{CF}$ at 3 weeks of age, with a sweat chloride concentration of $107 \mathrm{mEq} / \mathrm{liter}$. She is pancreatic insufficient. Her height is $142 \mathrm{~cm}(<5 \%$ for age) and weight is $36 \mathrm{~kg}$ (25\% for age). Pulmonary function testing has revealed FVC of 1.83 liters ( $81 \%$ of predicted), and $\mathrm{FEV}_{1}$ of 1.47 liters $(73 \%$ of predicted). She recently developed intrahepatic biliary cirrhosis and liver failure and is awaiting a liver transplant.

Detection of $\Delta F 508$ Mutation by Reversed DotBlot Assay was done (Saiki et al., 1989). The patient considered here was identified through this technique as $\Delta \mathrm{F} 508 /$ unknown. Detection of the unknown mutation was done by analysis of CFTR mRNA. Nasal epithelial tissue was obtained from the patient and a normal subject by nasal scrape as previously described (Strong et al., 1992). RNA was extracted from nasal epithelial cells using RNAzol B (Tel Test), according to manufacturer's specifications. PCR amplification spanning the codon region of CFTR cDNA was performed through amplification of five overlapping Polymerase Chain Reactions (PCR) using CFTR primers (Table 1). The patient was found to be heterozygous for $\triangle F 508$ at the RNA level. Standard conditions were used for all PCRs (Sambrook et al., 1989) RT/PCR products were visualized in a $1 \%$ agarose gel. Chemical mismatch cleavage (CMC) was done as previously described (Strong et al., 1991) based on a modification of the published technique (Cotton et al., 1988; Grompe et al., 1989).

The cDNA fragment determined to have a mutation through the chemical mismatch cleavage was amplified, gel purified, and directly sequenced based on the method of Kretz et al. (1989) using the Sequenase 2.0 Kit (U.S. Biochemical Corp). CFTR exon 7 was amplified from genomic DNA from the patient, her parents, 25 normal chromosomes, and $25 \mathrm{CF}$ chromosomes by PCR with exon 7 specific primers: 5'AGACCATGCTCAGAT. CTTCCAT 3' and 5' GATCAGTTCTAATGAACTTTGC 3'. The PCR product was digested with Ddel and visualized on a $12 \%$ nondenaturing polyacrylamide gel.

The effect of the G314R mutation on $\mathrm{Cl}$ channel function was investigated by expressing the altered protein in Xenopus oocytes. The methodology has

Received December 1, 1994; accepted February 21, 1995.

*To whom reprint requests/correspondence should be addressed. 
been described in detail (Drumm et al., 1991; Smit et al., 1993). Expression assays were conducted under conditions previously shown to give rise to robust expression of CFTR-mediated $\mathrm{Cl}$-currents in oocytes injected with mRNA transcribed from wildtype CFTR or mutants such as $\Delta$ F508.

\section{RESULTS}

A mismatch was detected in the region of exons 1-7 (data not shown). The 1130-bp fragment was sequenced, and the substitution of $C$ for $G$ was detected at $1072 \mathrm{bp}$. This substitution resulted in the change of arginine for glycine at position 314 (G314R), which, according to the predicted topology of CFTR, lies in the $5^{\text {th }}$ putative membrane spanning segment. The substitution of arginine for glycine at 314 results in elimination of a Ddel site.

Restriction digest analysis revealed that the patient is heterozygous for this mutation. To determine if this substitution was found in additional normal chromosomes or CF chromosomes, DNA from our panel of CF parents was amplified and restriction analysis was performed. Of 25 normal chromosomes and $25 \mathrm{CF}$ chromosomes screened, none were identified as having this mutation. The purpose of the screening was to detect if this mutation occurs in high frequency. To our knowledge, this mutation has not been identified in other $\mathrm{CF}$ patients.

To determine if this mutation is maternal (native-American (Cherokee)/Caucasian) or paternal (Caucasian) in origin, DNA samples from both parents were obtained. Exon 7 of the patient and her parents' DNA was amplified and restriction digest analysis with Ddel was performed. The G314R mutation was identified as maternal (Fig. 1). The $\Delta \mathrm{F} 508$ mutation was shown to be paternal (data not shown). It would have been of interest to obtain DNA samples from the maternal grandparents to track further the ethnic background of the mutation; however, both of them are deceased.

A total of 35 oocytes from 10 different frogs were assayed in 10 different rounds of injection with G314R CFTR. Of these only two exhibited a detectable response ( $80 \mathrm{nA}$ as compared to $>800$ $\mathrm{nA}$ for wt) to the application of forskolin and IBMX. The response of one of these to forskolin and IBMX is shown in Figure 2. In contrast, oocytes that were injected with mRNA transcribed from the wt construct exhibited robust responses to the application of $10 \mu \mathrm{M}$ forskolin and $5 \mathrm{mM}$ IBMX. Because the results with G314R were largely negative, we also compared cAMP-induced $\mathrm{Cl}$ currents in oocytes expressing CFTRs in which

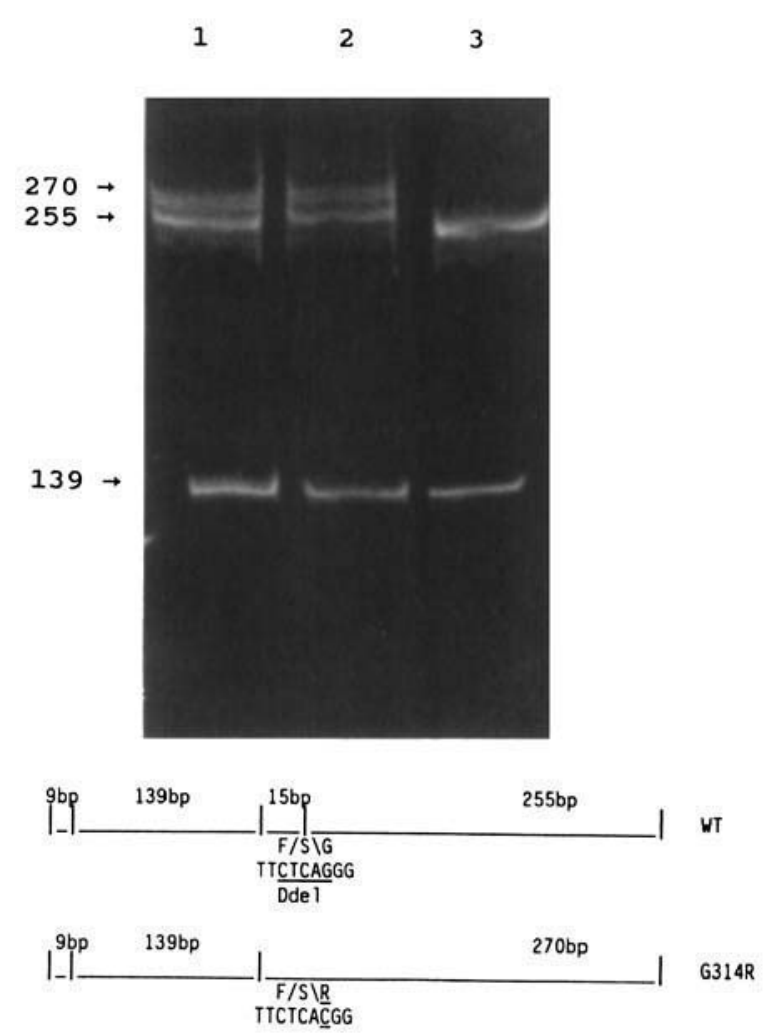

FIGURE 1. Restriction enzyme digestion analysis of exon 7 of CFTR of patient and parents. The upper panel shows digestion of PCR amplified exon 7 with the restriction enzyme Ddel generating the expected normal fragments of 255 and $139 \mathrm{bp}$. The predicted 15 and $9 \mathrm{bp}$ fragments are not visible in this analysis. In the case of the patient (lane 1) and mother (lane 2), an additional fragment of 270 bp is present (as is a faint heteroduplex), indicating the heterozygous loss of the Ddel site at codon 314. The lower panel shows a schematic representation of the restriction enzyme digest analysis of exon 7.

more conservative substitutions were made at the same position. CFTR constructs bearing either the G314A or G314E substitution were associated with readily discernable cAMP-induced $\mathrm{Cl}$ currents. The G314E substitution has been associated with cystic fibrosis (Golla et al., 1994).

\section{DISCUSSION}

Cystic fibrosis is characterized by viscous secretions in the tracheobronchial tree and pancreas leading to chronic pulmonary diseases and pancreatic insufficiency in most cases. Diagnosis is made by abnormal sweat electrolytes in most cases (Boat et al., 1989).

In this report we describe a patient with a nucleotide substitution in exon 7 in one CFTR allele and $\Delta F 508$ in the other allele. This mutation was not found in 25 normal chromosomes and $25 \mathrm{CF}$ 


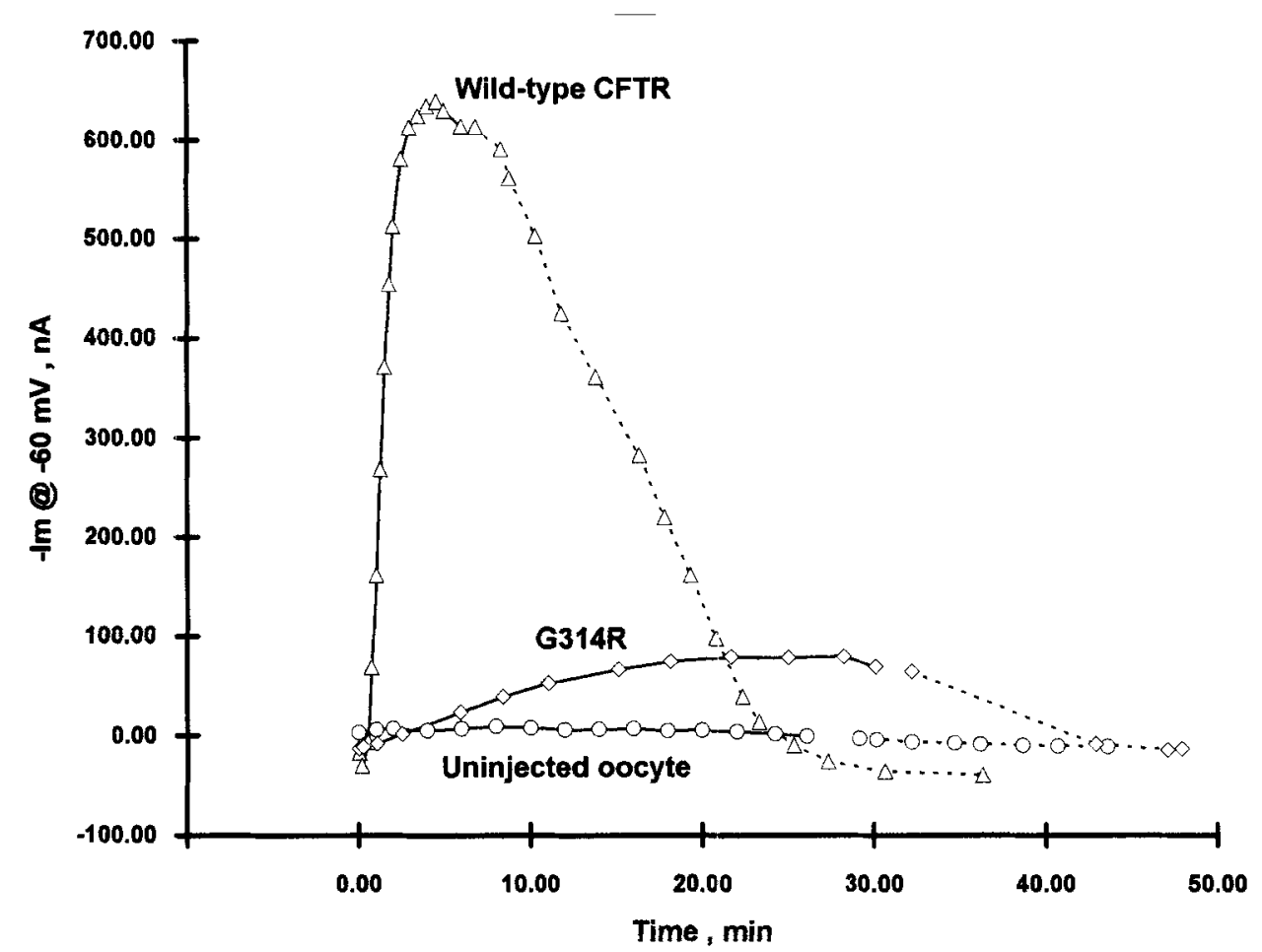

FIGURE 2. Membrane currents recorded from Xenopus oocytes at a holding potential of $-60 \mathrm{mV}$. Shown are records from oocytes previously injected with mRNA transcribed from wild-type $(-\triangle-)$ and G314R $\left(-\diamond_{-}\right)$CFTR along with a record from an uninjected oocyte (-O-). In each case, the oocyte was exposed to a stimulating cocktail containing $\mathbf{1 0}$ $M$ forskolin and $5 \mathrm{mM}$ IBMX, and the solid line shows the time course of activation of CFTR chloride current. The dashed lines show the time course for the inactivation of the current following removal of the stimulating cocktail.

TABLE 1. Oligonucleotides Used for Amplification of CFTR cDNA by PCR

\begin{tabular}{|c|c|c|}
\hline Fragment & Primer sequence & Exon \\
\hline 1 & 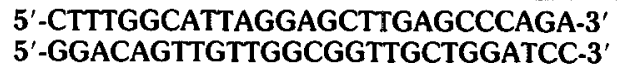 & $\begin{array}{l}1 \\
9\end{array}$ \\
\hline 1 Nested & $\begin{array}{l}\text { 5'-CCTAGCAGGGACCCCAGCGCCCGAGAG-3' } \\
\text { 5'-ACATGGTATGACTCTCTTGGAGCA-3' }\end{array}$ & 1 \\
\hline 2 & $\begin{array}{l}\text { 5'-CTGCGCATGGCGGTCACTCGGCA-3' } \\
\text { 5'-CATTAGAAGGAGATGCTCCTGTCTCCTG-3' }\end{array}$ & $\begin{array}{r}7 \\
13\end{array}$ \\
\hline 2 Nested & $\begin{array}{l}\text { 5'-GCATGGCGGTCACTCGGCAATTTC-3' } \\
\text { 5'-CATTAGAAGGAGATGCTCCTGTCTCCTG-3' }\end{array}$ & $\begin{array}{r}7 \\
13\end{array}$ \\
\hline 3 & $\begin{array}{l}5^{\prime} \text {-TGTGTCTGTAAACTGATGGCTAAC-3' } \\
5^{\prime} \text {-TCCTCCAAACCTCACAGCAACTCAAA-3' }\end{array}$ & $\begin{array}{l}13 \\
17\end{array}$ \\
\hline 3 Nested & $\begin{array}{l}\text { 5'-CTAGGATTTTGGTCACTTCTAAAATGG-3' } \\
\text { 5'-GACCTTCTGCCTCTTACCATATTTGA-3' }\end{array}$ & $\begin{array}{l}13 \\
16\end{array}$ \\
\hline 4 & $\begin{array}{l}\text { 5'-GTTGTGCTGTGGCTCCTTGGAA-3' } \\
\text { 5'-CAGTGGAGTGATCAAGAAATATGG-3' }\end{array}$ & $\begin{array}{l}14 \\
21\end{array}$ \\
\hline 4 Nested & $\begin{array}{l}\text { 5'-CTGGTGCATACTCTAATCACAGTGTC-3' } \\
\text { 5'-GCCTTTGGAGTGATACCACAGAAAG-3' }\end{array}$ & $20-21$ \\
\hline 5 & $\begin{array}{l}5^{\prime} \text {-CTCACAGCAAAATACACAGAAGGTG-3' } \\
5^{\prime} \text {-GCAGCATAAATGTTGACATGGGAC-3' }\end{array}$ & $\begin{array}{l}19 \\
24\end{array}$ \\
\hline 5 Nested & $\begin{array}{l}\text { 5'-GGCCTCTTGGGAAGAACTGGATCA-3' } \\
\text { 5'-GAAGAAGAGGTGCAAGATACAAGG-3' }\end{array}$ & $\begin{array}{l}20 \\
24\end{array}$ \\
\hline
\end{tabular}

chromosomes. The substitution of $\mathrm{G}$ to $\mathrm{C}$ results in a glycine to arginine substitution at amino acid 314 (G314R). This mutation is in the fifth putative hydrophobic transmembrane segment and results in the addition of a positive charge and a bulky side chain. The mutation is associated with severe disease and liver failure in our patient. The mutation, being maternal in origin, could be specific to the Cherokee CF population.

Expression of CFTR constructs bearing the 
G341R mutation in Xenopus oocytes provided evidence that this substitution severely compromises the $\mathrm{Cl}$ channel function of CFTR. Cyclic AMPactivated $\mathrm{Cl}$ currents were only barely detectable with this construct, whereas wt and $\triangle F 508$ CFTR, as well as variants bearing more conservative substitutions at the same site (G314A and G314E), were associated with the expression of significant $\mathrm{Cl}$ channel function.

Reduced expression of CFTR Cl channel function for $G 314 R$ could arise in at least two ways that are not mutually exclusive. The mutation could result in defective processing of the protein so that the amount of CFTR reaching the plasma membrane is reduced (Cheng et al., 1990). The mutation could also compromise the channel function by altering either the conduction and/or the gating properties of the CFTR Cl channels (Drumm et al., 1991; Sheppard et al., 1993). The data presented here do not distinguish between these alternatives, but it is noteworthy that $\triangle \mathrm{F} 508 \mathrm{CFTR}$, which is not delivered to the plasma membrane of mammalian cells at $37^{\circ} \mathrm{C}$, nevertheless gives rise to robust $\mathrm{Cl}$ channel activity in Xenopus oocytes (Drumm et al., 1991).

The location of the mutation in the predicted membrane spanning domain and the fact that it adds a net positive charge raises the possibility that the conduction properties of the channel could be compromised as shown previously for other mutations in this domain (Drumm et al., 1991; Sheppard et al., 1993).

Regardless of the mechanism, the combination of genetic and functional data presented here leaves little doubt that the G314R mutation is the cause of near total absence of CFTR $\mathrm{Cl}$ function and severe clinical disease in this patient.

\section{ACKNOWLEDGMENTS}

We thank the University of Michigan CF genotype core facility for the ELISA dot-blot screens for common $\mathrm{CF}$ mutations. This work was supported by grants from the Cystic Fibrosis Foundation (RDP MG 217) and the National Institutes of Health [DK45880 and DK29786 (DCD)].

\section{REFERENCES}

Boat TF, Welsh MJ, Beaudet AL (1989) Cystic Fibrosis. In Scriver CL, Beaudet A.L., Sly W.S., Valle D. (eds): The Metabolic Basis of Inherited Disease, 6th ed. New York: McGraw-Hill, pp 2649-2680.

Cheng SH, Gregory RJ, Marshall J, Paul S, Souza DW, White GA, O'Riordan CR, and Smith AE, (1990) Defective intra- cellular transport and processing of CFTR is the molecular basis of most cystic fibrosis. Cell 63:827-834.

Collins FS (1992) Cystic fibrosis: Molecular biology and therapeutic implications. Science 256:774-779.

Cotton RGH, Rodrigues NR, Campbell RD, (1988) Reactivity of cytosine and thymine in single base pair mismatches with hydroxylamine and osmium tetroxide and its application to the study of mutations. Proc Natl Acad Sci USA 85:4397-4401.

Drumm JL, Wilkinson DJ, Smit LS, Worrell RT, Strong TV, Frizzell RA, Dawson DC, and Collins FS (1991) Chloride conductance expressed by $\triangle F 508$ and other mutant CFTRs in Xenopus oocytes. Science 254:1797-1799.

Golla A, Deufel A, Aulehla-Scholz C, Bohm I, Hilz B, Meitinger $T$, Deufel T (1994) Identification of a novel missense mutation (G314E) in exon 7 of the cystic fibrosis transmembrane conductance regulator gene identified in a $\mathrm{CF}$ patient with pancreatic sufficiency. Hum Mutat 3:67-68.

Grompe M, Muzny DM, Caskey CT (1989) Scanning detection of mutations in human ornithine transcarbamylase by chemical mismatch cleavage. Proc Natl Acad Sci USA 86:5888-5892.

Kerem B-S, Rommens JM, Buchanan JA, Markiewicz D, Cox TK, Chakravarti, A, Buchwald M, Tsui L-C (1989) Identification of the cystic fibrosis gene: Genetic analysis. Science 245:10731080.

Kretz KA, Carson GS, O'Brien JS (1989) Direct sequencing from low-melt agarose with sequeriase. Nucl Acids Res 17:586-589.

Riordan JR (1993) The cystic fibrosis transmembrane conductance regulator. Annu Rev Physiol 55:609-630.

Riordan JR, Rommens JM, Kerem B, Alon N, Rozmahel R, Grzelczak Z, Zielenski J, et al. (1989) Identification of the cystic fibrosis gene: Cloning and characterization of the complementary DNA. Science 245:1066-1073.

Rommens JM, Iannuzzi MC, Kerem B, Drum ML, Melmer G, Dean M, Rozmahel R, et al. (1989) Identification of the cystic fibrosis gene: Chromosome walking and jumping. Science 245 : 1059-1065.

Saiki RK, Walsh PS, Levenson CH, Erlich HA (1989) Genetic analysis of amplified DNA with immobilized sequence-specific oligonucleotide probes. Proc Natl Acad Sci USA 86:6230_ 6234.

Sambrook J, Fritsch EF, Manniatis T, (eds) (1989) Molecular Cloning: A Laboratory Manual, 2nd ed. Cold Spring Harbor, New York: Cold Spring Harbor Laboratory Press, pp 14.14-14.20.

Sheppard DN, Rich DP, Ostedgaard LS, Gregory RJ, Smith AE, Welsh MJ (1993) Mutations in CFTR associated with milddisease-form Cl-channels with altered pore properties. Nature 362:160-164.

Smit LS, Wilkinson DJ, Mansoura MK, Collins, FS, Dawson, DC (1993) Functional Roles of the nucleotide-binding folds in the activation of cystic fibrosis transmembrane conductance regulator. Proc Natl Acad Sci USA 90:9963-9967.

Strong TV, Smit LS, Nasr S, Wood DL, Cole JL, Iannuzzi MC, Stern RC, Collins FS (1992) Chatacterization of an Intron 12 splice donor mutation in the cystic fibrosis transmembrane conductance regulator (CFTR) gene. Hum Mutat 1:380-387.

Strong TV, Smit LS, Turpin SV, Cole JL, TomHon C, Markiewicz D, Petty TL, et al. (1991) Custic fibrosis gene mutation in two sisters with mild disease and normal sweat electrolyte levels. $\mathrm{N}$ Engl J Med 325:1630-1634.

Welsh MJ (1990) Abnormal regulation of ion channels in cystic fibrosis epithelia. FASEB J 4:2718-2725.

Welsh MJ, Smith AE (1993) Molecular mechanisms of CFTR chloride channel dysfunction in cystic fibrosis. Cell 73:12511254. 